\title{
EDITORIAL
}

\section{JBO to Begin "e-First" Publication in 2005}

An exciting new change is imminent for the Journal of Biomedical Optics. Starting with the January 2005 issues, all SPIE journals will begin "e-First" publication. The primary objective of e-First publishing (also known as "article-at-atime" publishing) is to shorten the time from acceptance to publication.

In e-First publishing, individual journal articles are published online once the author proof corrections have been made and the editorial staff has approved the article for publication. The online table of contents for the issue builds as a partial table of contents while papers are being added to the issue. When the closing date of the issue is reached, the table of contents becomes complete and the print version of the journal is produced.

Readers who have access to the online version of JBO will therefore be able to read papers as much as several weeks earlier than in the past. This new approach, providing faster publication and reader access, along with publishing color in the online version of journal papers, are ways that SPIE is exploiting the capabilities of electronic publishing.

Deciding on e-First publishing required a rethinking of journal pagination. The traditional pagination scheme in which page numbers run consecutively from the first to the last issues of the volume year will be replaced with a scheme utilizing a unique six-digit article number in both the online and print versions of the journal, in order to allow the article to be fully cited as soon as it is published online, without waiting for the issue table of contents to be finalized. The article number scheme also allows the journal to maintain and organize section headings and to sequence papers within the table of contents, regardless of the order in which the papers are approved for publication.

The six-digit article number has three elements: the first two digits designate the issue number, the second two digits designate the subject/topic area or article type (e.g., editorial, letter, review paper), and the third two digits designate the sequence within that particular section. For example, JBO article number 014014 published in 2005 (Volume 10) would be interpreted as follows: The issue number " 01 " means it appears in the January/February 2005 issue; the second set of two digits "40" designates the topic section heading (e.g., Research Papers); "14" indicates that the article is the 14th article in the Research Papers topical section. With e-First, article no. 14 may very well be published prior to articles
$1-13$, but it will appear in its proper sequence as the online issue builds and in the resulting print journal.

Citations to articles published in JBO beginning with the January/February 2005 issue should be formatted using the volume and six-digit article code, rather than volume and page number; for example, J. Biomed. Opt. 10, 014014 (2005) refers to the example article above.

Within each article, the pages will be numbered consecutively with a hyphen following the article number, for example, 014014-1, 014014-2, 014014-3,... . However, only the six-digit article number should be used when citing the article (i.e., the hyphen and subsequent digits should not be used in citations).

As part of the change to e-First publishing, the publication timeline for the print journal has also been adjusted. The print issues now appear at the end of the month, rather than at the beginning of the month. For example, the January/February 2005 issue will be printed and mailed in March, and the next issue (March/April 2005) will be printed and mailed in May. The cover date reflects the date that the articles in that issue appeared online, rather than the date of print publication. For instance, the March/April 2005 issue will contain all the articles that appear online between 1 March and 30 April 2005.

The Journal of Biomedical Optics, along with SPIE's other three journals (Optical Engineering, the Journal of Electronic Imaging, and the Journal of Microlithography, Microfabrication, and Microsystems) can be accessed through the SPIE Digital Library at www.spiedl.org. All issues published since 1998 are currently online, and the archives going back to 1990 will be added very soon. You can search and browse any and all of the journals online. We encourage readers to use this resource.

\section{Bruce J. Tromberg Editor-in-Chief}

\section{Publisher's Note:}

The annual Author and Subject indexes that have previously been printed in the last issue of each volume have been discontinued, due to the availability of metadata searching in the online version of this journal. SPIE journal articles published from 1998 to the current issue can be searched online using the SPIE Digital Library (http://www.spiedl.org). A subscription is not required to use the search and browse features or to view tables of contents and abstracts. Downloading of full-text digital papers is available only to subscribers. 